\title{
Self-Measured vs Professionally Measured Waist Circumference
}

\author{
Barbara G. Carranza Leon, $M D^{1,2}$ \\ Michael D. Jensen, $M D^{1}$ \\ Jennifer J. Hartman, $M D^{3}$ \\ Teresa B. Jensen, $M D^{3}$ \\ 'Endocrine Research Unit, Mayo Clinic, \\ Rochester, Minnesota \\ ${ }^{2}$ Division of Diabetes, Endocrinology \& \\ Metabolism, Vanderbilt University Medical \\ Center, Nashville, Tennessee \\ ${ }^{3}$ Department of Family Medicine, Mayo \\ Clinic, Rochester, Minnesota
}

Conflicts of interest: authors report none.

\section{CORRESPONDING AUTHOR}

Teresa B. Jensen, MD

Department of Family Medicine

Mayo Clinic

2001 st St SW

Rochester, MN 55905

jensen.teresa@mayo.edu

\begin{abstract}
PURPOSE Although waist circumference can provide important metabolic risk information, logistic issues inhibit its routine use in outpatient practice settings. We assessed whether self-measured waist circumference is sufficiently accurate to replace professionally measured waist circumference for identifying high-risk patients.
\end{abstract}

METHODS Medical outpatients and research participants self-measured their waist circumference at the same visit during which a professionally measured waist circumference was obtained. Participants were provided with standardized pictorial instructions on how to measure their waist circumference, and professionals underwent standard training.

RESULTS Self- and professionally measured waist circumference data were collected for 585 women (mean \pm SD age $=40 \pm 14$ years, mean \pm SD body mass index $=27.7 \pm 6.0 \mathrm{~kg} / \mathrm{m}^{2}$ ) and 165 men (mean $\pm S D$ age $=41 \pm 14$ years, mean \pm SD body mass index $=29.3 \pm 4.6 \mathrm{~kg} / \mathrm{m}^{2}$ ). Although self- and professionally measured waist circumference did not differ significantly, we found a clinically important false-negative rate for the self-measurements. Eleven percent of normal-weight and $52 \%$ of overweight women had a professionally measured waist circumference putting them in a high-risk category for metabolic syndrome (ie, greater than $88 \mathrm{~cm}$ ); however, $57 \%$ and $18 \%$ of these women, respectively, undermeasured their waist circumference as falling below that cutoff. Fifteen percent and $84 \%$ of overweight and class I obese men, respectively, had a professionally measured waist circumference putting them in the high-risk category (ie, greater than $102 \mathrm{~cm}$ ); however, $23 \%$ and $16 \%$ of these men, respectively, undermeasured their waist circumference as falling below that cutoff.

CONCLUSIONS Despite standardized pictorial instructions for self-measured waist circumference, the false-negative rate of self-measurements approached or exceeded $20 \%$ for some groups at high risk for poor health outcomes.

Ann Fam Med 2016;14:262-266. doi: 10.1370/afm.1896.

\section{INTRODUCTION}

$\mathrm{O}$ verweight and obesity are common problems seen in the primary care setting. Body mass index (BMI) is used to identify people at increased risk for weight-related problems, but abdominal fat, an even better risk marker, can vary dramatically within a narrow range of BMIs. Measuring waist circumference can improve the predictive value of the BMI. ${ }^{1-3}$ The guidelines for managing overweight and obesity in adults recommend waist circumference be measured if an individual's BMI is 25 to less than $35 \mathrm{~kg} / \mathrm{m}^{2}$ to provide additional cardiometabolic risk information. ${ }^{4}$

Despite these recommendations, implementing routine waist circumference measures in the practice setting requires additional efforts by office personnel. Having patients measure their own waist circumference is one solution, but perhaps because of the use of paper measuring tapes or comparisons of home measurements with those done at the clinic, mixed results have been reported. ${ }^{5-8}$ Preliminary data, however, suggest that recent improvements in the instructions and equipment ${ }^{9}$ may have solved these problems. 
We reasoned that if patients can reliably measure their own waist circumference in outpatient settings, doing so could facilitate implementation of these data into busy primary care practices. We therefore assessed whether self-measured waist circumference is sufficiently accurate to replace professionally measured waist circumference as a screening tool for metabolic syndrome. A secondary aim of this study was to determine if certain populations (men or women, younger or older) are more accurate in ascertaining self-measured waist circumference in the event that, as a group, adult outpatients did not perform sufficiently well.

\section{METHODS}

\section{Participants}

Participants were recruited between January 2008 and December 2011 from patients making outpatient medical visits to the Mayo Clinic Family Medicine practice, Rochester, Minnesota, and from volunteers coming to the outpatient Clinical Research Unit at the Mayo Clinic Hospital, St Marys Campus, for screening interviews. Participants were chosen from those coming to the clinic for any type of appointment (routine or acute care visits) or for enrollment in unrelated research studies. Criteria for inclusion were being aged 18 years or older, not pregnant or within 3 months of delivery, no abdominal surgeries within the preceding 6 weeks, ability to stand for measurements, ability to understand written and verbal instructions, and ability to give informed consent. The Mayo Clinic institutional review board approved this research protocol. Participants whose primary language was not English gave consent in their native language and, because the measurement instructions were only in picture form, were not excluded on the basis of their primary language.

\section{Measurements}

After being told about the aim of the study and consenting to participate, participants were given pictorial instructions for self-measuring their waist circumference. They were not assisted by the professionals, and measurements using mirrors were not allowed. Participants were told to follow the pictorial instructions; those in the outpatient clinic were asked to write the result on a piece of paper supplied and give it to the professional when done, while those in the research unit reported the result verbally. No time limit was given.

The professional measurement was performed immediately afterward by professional personnel (a clinical assistant, licensed practical nurse, registered nurse, doctor of philosophy, or medical doctor) who were unaware of the patient-measured results. Each professional measurer received video as well as written and pictorial instructions on proper performance of these measurements and underwent training by the study principal investigator. For this study, waist circumference was measured at the level of the iliac crest with the participants in a standing position.

All measurements were performed using the MyoTape (AccuFitness, LLC) on bare skin or over thin garments. Collected data included height, weight, birth date, setting (clinical vs research), sex, and waist circumference (both self-measured and professionally measured).

\section{Data Analysis}

Data were analyzed collectively and separately for men and women. Means and standard deviations of waist circumference are reported for the entire group. Paired $t$ tests were used to assess statistically significant differences between self- and professionally measured values. Because mean differences were calculated as self-measurement minus professional measurement, a positive mean difference indicated that the professional measurement was less than the self-measurement. We used Bland-Altman plots to examine the individual agreement between self-measured and professionally measured values; the differences between the 2 values (self-measured minus professionally measured) were plotted against the professionally measured value. The difference between self- and professional measurements was used as the dependent variable in a mixed model, multivariate regression analysis. To determine which variables to include, we performed univariate, sexspecific linear regression analyses examining the relationship between age, weight, and BMI, and the difference between self-reported and professionally reported measurements. Variables with $P$ values less than .10 (weight and BMI met this criterion) were included in the multivariate regression model. The multivariate model we tested thus included sex, setting (clinical vs research), weight, and BMI as independent variables.

\section{RESULTS}

A total of 750 individuals participated in this study. Table 1 provides the participants' characteristics. The mean and standard deviation of the self-measured and professionally measured waist circumference are shown in Table 2. Multivariate regression analysis did not detect any significant relationships between sex, setting (clinical vs research), weight, or BMI and errors in self-measured waist circumference. Age was not significantly associated with the difference between self- and professionally measured waist circumference $(P>.10$ for both men and women). 
The Bland-Altman plots (Figures 1a and 1b) illustrate the agreement between professional measurements and the difference between self- and professional measurements. For both men and women, most points lie within the $95 \%$ limits of agreement.

Data regarding rates of underestimation of waist circumference are provided in Table 3. Fifty-seven percent of normal-weight women with a professionally measured waist circumference putting them in a highrisk category for metabolic syndrome (ie, greater than $88 \mathrm{~cm}$ ) undermeasured their waist circumference by an amount sufficient to falsely place them in the low-risk category. Eighteen percent of overweight women with a professionally measured waist circumference greater than $88 \mathrm{~cm}$ had a self-measured value that was less than this cutoff.

None of the normal-weight men in this sample had a professionally measured waist circumference putting them in the high-risk category for metabolic syndrome (ie, greater than $102 \mathrm{~cm}$ ) (Table 3). Sixteen percent of overweight men and $84 \%$ of class I obese men did, however. Twenty-three percent of overweight men and $16 \%$ of class I obese men with a professionally measured waist circumference of greater than 102

\begin{tabular}{|c|c|c|}
\hline Characteristic & $\begin{array}{l}\text { Women } \\
(n=585)\end{array}$ & $\begin{array}{c}\text { Men } \\
(n=165)\end{array}$ \\
\hline Age, mean (SD), y & $40(14)$ & $41(14)$ \\
\hline BMI, mean (SD), kg/m² & $27.7(6.0)$ & $29.3(4.6)$ \\
\hline \multicolumn{3}{|l|}{ Setting, No. (\%) } \\
\hline Clinical & $481(82.2)$ & $114(69.1)$ \\
\hline Research & $104(17.8)$ & $51(30.9)$ \\
\hline \multicolumn{3}{|l|}{ BMI category, No. (\%) } \\
\hline$<18.5 \mathrm{~kg} / \mathrm{m}^{2}$ (underweight) & $6(1.0)$ & $0(0)$ \\
\hline $18.5-24.9 \mathrm{~kg} / \mathrm{m}^{2}$ (normal weight) & $213(36.4)$ & $24(14.5)$ \\
\hline $25-29.9 \mathrm{~kg} / \mathrm{m}^{2}$ (overweight) & $180(30.8)$ & $82(49.8)$ \\
\hline $30-34.9$ kg/m² (class I obese) & $112(19.1)$ & $37(22.4)$ \\
\hline $35-39.9$ kg/m² (class II obese) & $52(8.9)$ & $17(10.3)$ \\
\hline$\geq 40 \mathrm{~kg} / \mathrm{m}^{2}$ (class III obese) & $22(3.8)$ & $5(3.0)$ \\
\hline
\end{tabular}

$\mathrm{cm}$ undermeasured their waist circumference by an amount sufficient to falsely place them in the low-risk category.

Sixty-two percent of the women and $38 \%$ of the men with a BMI of 18.5 to $25 \mathrm{~kg} / \mathrm{m}^{2}$ were within $2 \mathrm{~cm}$ of the professional waist circumference measurement. Similarly, $60 \%$ of women and $44 \%$ of men with a BMI of 25 to $30 \mathrm{~kg} / \mathrm{m}^{2}$ were within $2 \mathrm{~cm}$ of the professional waist circumference measurement.

\section{DISCUSSION}

We assessed whether self-measured waist circumference can be used to screen for metabolic risk and thereby reduce the time needed to perform office health screening. We provided standardized waist circumference measurement instructions to patients and potential research participants, and compared their results with those made immediately thereafter by trained professionals. Although we found no significant differences in mean values between self- and professionally measured waist circumference, a worrisome proportion of patients misclassified themselves as low risk using self-measured waist circumference.

The finding that $57 \%$ of women with normal weight, $18 \%$ of overweight women, and $23 \%$ of overweight men with high-risk waist circumference by professional measurement would have been falsely categorized as low risk by self-measurement is of concern. We argue that this is an unacceptable proportion of patients who would not be further screened for metabolic syndrome if only self-measured waist circumference numbers were used. Because diabetes and dyslipidemia, both strong cardiovascular risk factors, are associated with abdominal adiposity, it seems prudent to use professionally measured waist circumference at patient encounters to determine whether further metabolic syndrome testing is warranted.

Ours appears to be the first report comparing selfmeasurement of waist circumference with professional measurement in a clinical setting ${ }_{i}$ in most previous studies, participants measured their waist circumference at home or during a health fair. ${ }^{10,11}$ We had a wide range of participant ages and BMI in this study. The use of the new MyoTape may have helped improve consistency by providing an easy way to measure waist circumference without extensive instruction. We were interested to observe that approximately $11 \%$ of women with a BMI in the normal weight category had a 
Figure 1a. Agreement of self-measured and professionally measured waist circumference among women.

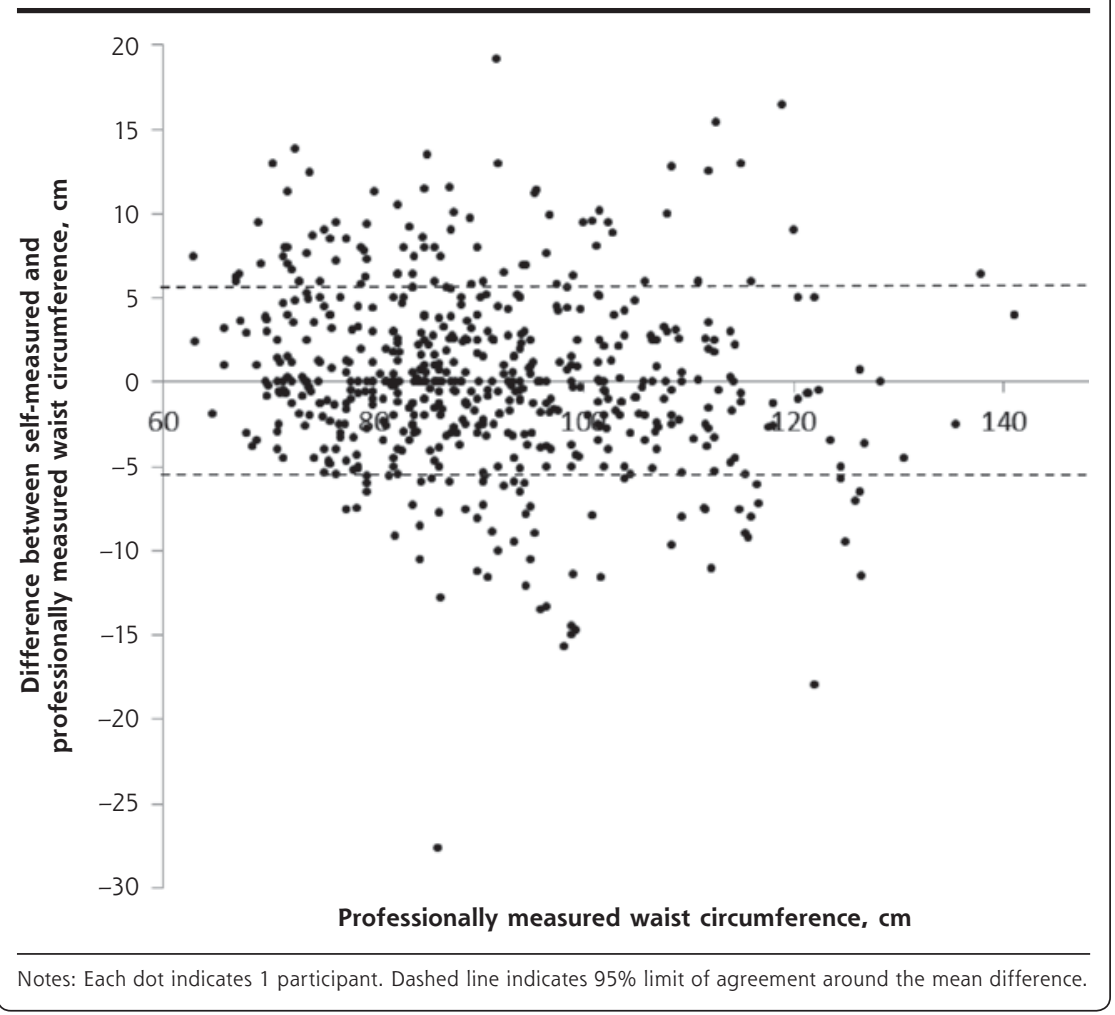

Figure 1b. Agreement of self-measured and professionally measured waist circumference among men.

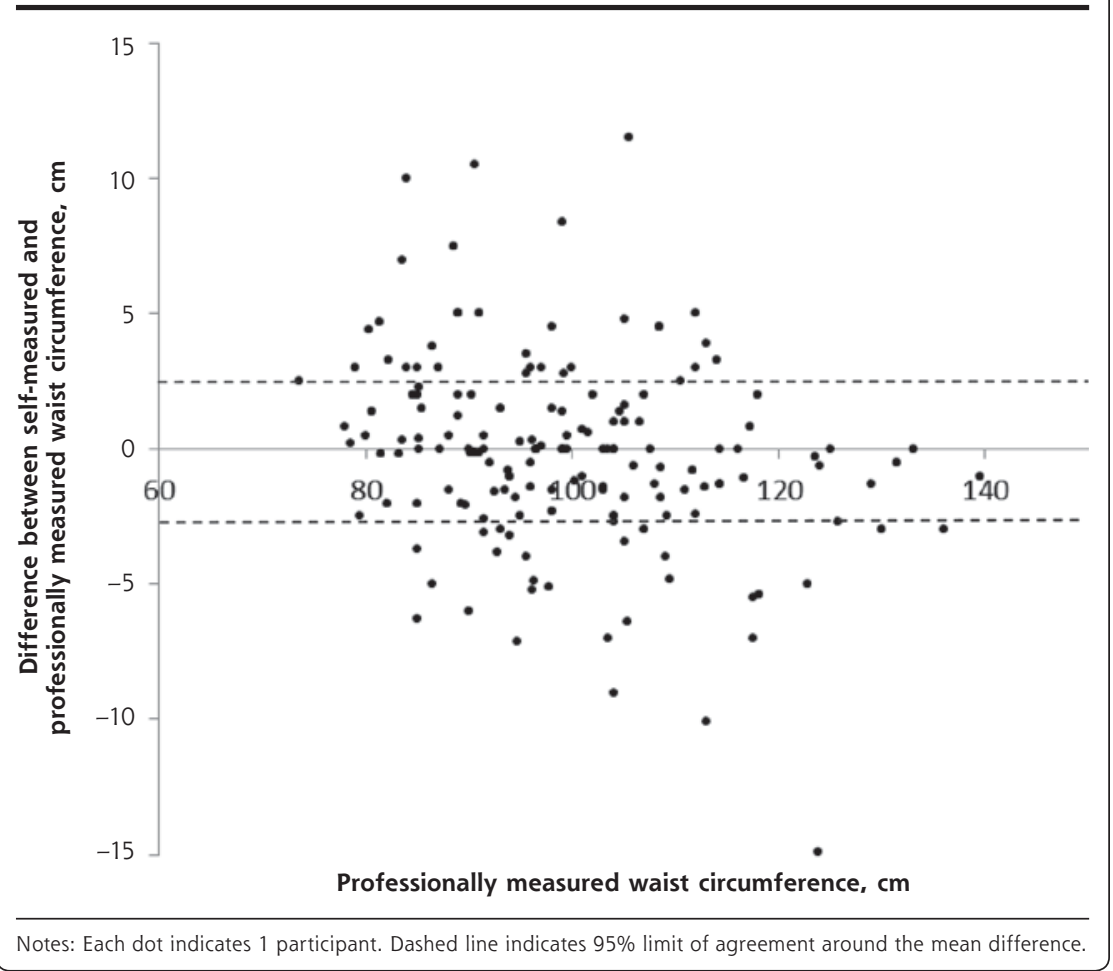

professionally measured waist circumference of greater than $88 \mathrm{~cm}$. To the extent that our results can be extrapolated to other outpatient settings, the use of the self-reported waist circumference measurements might misclassify $5 \%$ of normal-weight women as being in a lower-risk category. Different results have been reported for women and men when comparing self- with professional measurements. One group found that patients overestimate their waist circumference compared with professionals, ${ }^{5}$ whereas others have found that both sexes tend to comparatively underestimate this metric. ${ }^{12,13}$ In 1 study, women, but not men, underestimated their waist circumference. ${ }^{14}$

Although Han and Lean ${ }^{8}$ reported better accuracy among younger adults, we did not detect any relationship between age and measurement error. A trend of decreasing accuracy with increasing body size in self-reported waist circumference has also been reported ${ }^{12,13}$; we found a similar trend in our sample, but it was not statistically significant.

Despite the advantages of using the waist circumference metric, many problems exist. Few individuals are properly trained, and there is no consensus on an accepted waist circumference measurement site on the body. Self-reports have the advantage of practicality and low cost. Individuals can be taught to correctly perform the waist circumference measurement on themselves through personal instruction from a trained professional, but this teaching is time consuming and has limited potential to reach the majority of the public. A computer-based 
Table 3. Risk Classification by Waist Circumference Among Women and Men

\begin{tabular}{|c|c|c|c|}
\hline BMI Category & $\begin{array}{l}\text { Participants, } \\
\text { No. }\end{array}$ & $\begin{array}{c}\text { High Risk }{ }^{a} \text { by } \\
\text { Professionally } \\
\text { Measured WC, } \\
\text { No. (\%) }\end{array}$ & $\begin{array}{c}\text { Not High Risk }{ }^{a} \text { by } \\
\text { Self-Measured WC, } \\
\text { No. }(\%)^{b}\end{array}$ \\
\hline \multicolumn{4}{|l|}{ Women } \\
\hline Normal weight & 213 & $23(10.7)$ & $13(56.5)$ \\
\hline Overweight & 180 & $93(51.7)$ & $17(18.1)$ \\
\hline Class I obese & 112 & $109(97.3)$ & $8(7.3)$ \\
\hline \multicolumn{4}{|l|}{ Men } \\
\hline Normal weight & 24 & $0(0.0)$ & $0(0.0)$ \\
\hline Overweight & 82 & $12(14.6)$ & $3(23.1)$ \\
\hline Class I obese & 37 & $31(83.8)$ & $5(16.1)$ \\
\hline \multicolumn{4}{|c|}{$\mathrm{BMI}=$ body mass index; $\mathrm{WC}=$ waist circumference. } \\
\hline \multicolumn{4}{|c|}{$\begin{array}{l}\text { a Cutoff for high risk: greater than } 88 \mathrm{~cm} \text { for women and greater than } 102 \mathrm{~cm} \text { for men. } \\
\text { b Among those at high risk according to the professional measurement. }\end{array}$} \\
\hline
\end{tabular}

Prior presentations: This work was presented in a poster at The Obesity Society annual meeting 2012, September 20-24, 2012, San Antonio, Texas.

Acknowledgments: We would like to thank Carley Vrieze for her assistance with these measurements.

\section{References}

1. Gelber RP, Gaziano JM, Orav EJ, Manson JE, Buring $\mathrm{JE}$, Kurth T. Measures of obesity and cardiovascular risk among men and women. J Am Coll Cardiol. 2008;52(8):605-615.

2. Jacobs EJ, Newton CC, Wang Y, et al. Waist circumference and all-cause mortality in a large US cohort. Arch Intern Med. 2010;170(15):1293-1301.

3. Wang Y, Rimm EB, Stampfer MJ, Willett WC, Hu FB. Comparison of abdominal adiposity and overall obesity in predicting risk of type 2 diabetes among men. Am J Clin Nutr. 2005;81(3):555-563.

4. Jensen MD, Ryan DH, Apovian CM, et al; American College of Cardiology/American Heart Association

tutorial for waist circumference self-measurement has been shown to be a valid tool for teaching this task and could be used in the future. ${ }^{14}$

In this study, we accepted a single professional measurement as the standard measurement. This approach is a limitation because we were not able to independently (via a third, trained measurer) assess the accuracy of this measurement. A second limitation is that we did not obtain duplicate measures from patients or professionals on separate occasions. Multiple measurements would have provided more information but would also have strayed from a realistic office setting.

In summary, we found that self-measured waist circumference has an unacceptably high rate of underestimation to be used for assessing metabolic risk. If self-measured waist circumference is going to be substituted for professional measurement, further research on how to improve instruction techniques or measuring devices will be needed.

To read or post commentaries in response to this article, see it online at http://www.annfammed.org/content/14/3/262.

Key words: metabolic syndrome; anthropometrics; obesity; waist circumference; risk assessment; primary care; practice-based research

Submitted May 7, 2015; submitted, revised, October 8, 2015; accepted November 8, 2015.

Funding support: This work was supported by grant NCRR UL1 TR000135; by National Institutes of Health grants DK-45343, DK-40484, and DK-50456; and by funding from the Department of Family Medicine, Mayo Clinic. Task Force on Practice Guidelines; Obesity Society. 2013 AHA/ACC/ TOS guideline for the management of overweight and obesity in adults: a report of the American College of Cardiology/American Heart Association Task Force on Practice Guidelines and The Obesity Society. Circulation. 2014;129(25)(Suppl 2):S102-S138.

5. Kushi LH, Kaye SA, Folsom AR, Soler JT, Prineas RJ. Accuracy and reliability of self-measurement of body girths. Am J Epidemiol. 1988;128(4):740-748.

6. Bigaard J, Spanggaard I, Thomsen BL, Overvad K, Tjønneland A. Self-reported and technician-measured waist circumferences differ in middle-aged men and women. J Nutr. 2005;135(9):2263-2270.

7. Booth ML, Hunter C, Gore CJ, Bauman A, Owen N. The relationship between body mass index and waist circumference: implications for estimates of the population prevalence of overweight. Int J Obes Relat Metab Disord. 2000;24(8):1058-1061.

8. Han TS, Lean MEJ. Self-reported waist circumference compared with the 'Waist Watcher' tape-measure to identify individuals at increased health risk through intra-abdominal fat accumulation. $\mathrm{Br} J$ Nutr. 1998; 80(1):81-88.

9. Prince SA, Janssen I, Tranmer JE. Self-measured waist circumference in older patients with heart failure: a study of validity and reliability using a MyoTape. J Cardiopulm Rehabil Prev. 2008;28(1):43-47.

10. Rimm EB, Stampfer MJ, Colditz GA, Chute CG, Litin LB, Willett WC. Validity of self-reported waist and hip circumferences in men and women. Epidemiology. 1990;1(6):466-473.

11. Reidpath DD, Cheah JC, Lam FC, Yasin S, Soyiri I, Allotey P. Validity of self-measured waist and hip circumferences: results from a community study in Malaysia. Nutr J. 2013;12:135.

12. Weaver TW, Kushi LH, McGovern PG, et al. Validation study of selfreported measures of fat distribution. Int J Obes Relat Metab Disord. 1996;20(7):644-650.

13. Spencer EA, Roddam AW, Key TJ. Accuracy of self-reported waist and hip measurements in 4492 EPIC-Oxford participants. Public Health Nutr. 2004;7(6):723-727.

14. Elliott WL. Criterion validity of a computer-based tutorial for teaching waist circumference self-measurement. J Bodyw Mov Ther. 2008;12(2):133-145. 